Elsevier required licence: $(c)<2018>$. This manuscript version is made available under the CC-BY-NC-ND 4.0 license http://creativecommons.org/licenses/by-nc-nd/4.0/ 


\title{
Effect of fluctuating hydraulic retention time (HRT) on denitrification in the UASB reactors
}

\author{
Wenyu Niu ${ }^{\text {, }}$ Jianbo Guo ${ }^{\mathrm{a}, \mathrm{b}, *}$, Jing Lian ${ }^{\mathrm{b}}$, Huu Hao $\mathrm{Ngo}^{\mathrm{c}}$, Haiyan $\mathrm{Li}^{\mathrm{d}}$, Yuanyuan Song ${ }^{\mathrm{a}}$, \\ Haibo Lia, Pengna Yin ${ }^{a}$ \\ ${ }^{a}$ Tianjin Key Laboratory of Aquatic Science and Technology, School of Environmental and Municipal Engineering, Tianjin Chengjian University, Jinjing Road \\ 26\#, Tianjin 300384, PR China \\ ${ }^{\mathrm{b}}$ School of Environmental Science and Engineering \& Pollution Prevention Biotechnology Laboratory of Hebei Province, Hebei University of Science and \\ Technology, Yuhua East Road 70\#, Shijiazhuang 050018, PR China \\ ${ }^{c}$ Centre for Technology in Water and Wastewater, School of Civil and Environmental Engineering, University of Technology Sydney, Ultimo, NSW 2007, \\ Australia \\ ${ }^{\mathrm{d}}$ Beijing Engineering Research Center of Sustainable Urban Sewage System Construction and Risk Control, Beijing University of Civil Engineering and \\ Architecture, Beijing 100044, China
}

\section{a rticle info}

\section{Article history:}

Received 26 September 2017

Received in revised form

25 December 2017

Accepted 27 December 2017

Available online 28 December 2017

\section{Keywords:}

Fluctuation HRT

Microbial community

AHLs

Denitrifying sludge granulation

Performance

\begin{abstract}
a b s t r a c t
This study cultivated denitrifying granular sludge in three up-flow anaerobic sludge blanket (UASB) reactors using different fluctuation hydraulic retention time (HRT) strategies (reactor 1 ( $\mathrm{R}_{\mathrm{C}}$ ): constant HRT (C-HRT); reactor $2\left(\mathrm{R}_{\mathrm{DF}}\right)$ : downward fluctuation HRT (DF-HRT); and reactor 3 (RUF): upward fluctuation HRT (UF-HRT)). The results verified that these fluctuation HRT strategies could enhance microbial diversity, while robust against fluctuations in nutrient load of the denitrifying granular sludge. Microbial aggregates appeared in $R_{C}, R_{U F}$ and $R_{D F}$ on days 22, 12 and 7, respectively. The sludge in $R_{U F}$ and $R_{D F}$ achieved complete granulation on days 22 and 14, respectively. Compared to the results of $R_{C}$ and $R_{U F}$, the acyl homoserine lactones (AHLs) concentration rapidly increased, and changed the components of extracellular polymeric substances (EPS) resulted in the rapid formation of denitrifying granular sludge in $\mathrm{R}_{\mathrm{DF}}$. These results demonstrate that microbial community, AHLs, EPS, and the denitrifying sludge granulation process were associated with each other. Informed from quorum sensing system, a mechanism for the granulation of denitrifying sludge using the DF-HRT strategy was proposed. The DF-HRT strategy is an economical and fast method to cultivate denitrifying granular sludge. We hope that the results of our research would provide some theoretical support for wastewater producing unstable plants.
\end{abstract}

(C) 2017 Elsevier B.V. All rights reserved.

\section{Introduction}

Severe environmental problems will occur if nitrate compounds are discharged into the environment, including eutrophication of rivers, deterioration of water sources, and direct hazards to human health [1]. Biological denitrification is the preferred pathway for the removal of nitrogen pollution in water systems, which describes the sequential reduction of nitrate or nitrite to dinitrogen gas, via the gaseous intermediates nitric oxide and nitrous oxide [2]. However, the key disadvantages of activate sludge denitrification are its slow start-up time, low nitrogen load, and low efficiency. Den-

\footnotetext{
* Corresponding author at: Tianjin Key Laboratory of Aquatic Science and Technology, School of Environmental and Municipal Engineering, Tianjin Chengiian
} University, Jinjing Road 26\#, Tianjin 300384, PR China. itrifying granular sludge is an important means to remedy these disadvantages.

Denitrification process often face variations in hydraulic retention time (HRT), caused by abrupt changes of wastewater characteristics and production. HRT often exerts profound effects on the performance of biological treatment systems [3,4]. HRT also profoundly influences the hydraulic shear force and the contact time among different pollutants within a reactor. Moreover, HRT can also affect the components of extracellular polymeric substances (EPS), microbial activity, and microbial community $[3,5]$. Denitrifying granular sludge formation and performance have also been reported to be markedly affected by HRT [6,7]. Withincreasing HRT, the formation time of denitrifying granular sludge shortens, while enhancing nitrogen removal [8]. However, if the HRT is too short, the activated sludge would not be able to form denitrifying 
granular due to the excessive hydraulic shear force, washing out the activated sludge [9]. In contrast, if HRT is too long, treatment efficiency would decrease and denitrifying granular sludge would not be formed [10,11]. Zhang et al. [12] reported that HRT could affect microbial community structure, which was closely connected with quorum sensing (QS) systems.

In addition, increasing evidence indicated that QS was strongly related to reactor performance, EPS content and sludge granulation $[13,14]$. A further study showed that QS in activated sludge flocs could regulate both reactor performance and EPS content, and accelerating sludge granulation through a response to changes in the concentration of acyl homoserine lactones (AHLs) [15]. Moreover, QS is closely related to the external environment, and the disturbed external environment could severely affect QS [14,15]. Sun et al. [14] and Yang et al. [16] provided intermittent feeding and starvation strategies that severely affected the QS system. Even though extensive research has been investigate the relationship between the reactor operating conditions and the QS, few studies researched the relationship between the QS and the fluctuation HRT. Therefore, uncoupling the effects of thefluctuationHRT, microbial community, and AHLs is quite necessary, especially on the granulation of denitrifying sludge with a fast formation strategy.

Accordingly, the objectives of this study were primarily: (1) to investigate the effect of fluctuating HRT on the performance of up-flow anaerobic sludge blanket (UASB) reactors for biological nitrate reduction; (2) to determine whether fluctuation HRT, microbial community, AHLs, EPS and the denitrifying granulation process were associated and to explore the mechanism of granular sludge denitrification; and (3) to identify and comprehensive analysis primary functional denitrifiers in the UASB during operation under fluctuation HRT conditions.

\section{Materials and methods}

\subsection{Reactor setup and operation}

Three UASB reactors were set up to cultivate the denitrifying granular sludge using different HRTs: reactor $1\left(R_{C}\right)$ used constant HRT (C-HRT), reactor $2\left(R_{D F}\right)$ used downward fluctuation HRT (DF-HRT), and reactor 3 (RUF) used upward fluctuation HRT (UF-HRT). The reactor size of all three reactors was approximately $3.5 \mathrm{~L}$ with an internal diameter of $6.8 \mathrm{~cm}$ and a height of $60 \mathrm{~cm}$. The activated sludge for inoculation was obtained from the return sludge-thickening tank of the Xianyang Road Wastewater Treatment Plant of Tianjin, China. Mixed liquor suspended solids (MLSS) and mixed liquor volatile suspended solids (MLVSS) were $13.8 \underline{\oplus} .6 \mathrm{~g} \mathrm{~L}^{-1}$ and $8.9 \underline{\Theta} .4 \mathrm{~g} \mathrm{~L}^{-1}$, respectively. The process started with denitrified synthetic wastewater containing $\left(\mathrm{mgL}^{-1}\right) \mathrm{CH}_{3} \mathrm{OH}$, $\mathrm{NaNO}_{3}, \mathrm{KH}_{2} \mathrm{PO}_{4}$, and $0.01\left(\mathrm{~mL} \mathrm{~L}^{-1}\right)$ microelement solution. $\mathrm{CH}_{3} \mathrm{OH}$ was provided as organic carbon and NO- 3 acted as electron acceptor. The microelementsolutioncontained thefollowingcompounds $\left(\mathrm{g} \mathrm{L}^{-1}\right): 0.43 \mathrm{ZnSO}_{4} \cdot 7 \mathrm{H}_{2} \mathrm{O}, 0.014 \mathrm{H}_{3} \mathrm{BO}_{4}, 0.99 \mathrm{MnCl}_{2} \cdot 4 \mathrm{H}_{2} \mathrm{O}, 0.25$ $\mathrm{CuSO}_{4} 5 \mathrm{H}_{2} \mathrm{O}, 0.19 \mathrm{NiCl}_{2} 6 \mathrm{H}_{2} \mathrm{O}$ and $0.24 \mathrm{CoCl}_{2} 6 \mathrm{H}_{2} \mathrm{O}$.

The reactors were operated for 30 days to investigate the effects of fluctuation HRT on denitrifying sludge granulation and performance. The operation processes of the three reactors were divided into two periods: the acclimatization period and the examination period (as shown in Table 1). In the acclimatization period, the HRT of $R_{C}$ remained at $3.5 \mathrm{~h}$ throughout the period, while the $R_{D F}$ had an HRT of 3.5 h on odd days, and sudden change to 1.75 h on even days, and the R $\mathrm{R}_{\mathrm{UF}}$ had an HRT of $3.5 \mathrm{~h}$ on odd days, and sudden change to $7 \mathrm{~h}$ on even days. In the examination period, the influent NO3-N concentrations of the three reactors was gradually raised from $100 \mathrm{mg} \mathrm{L}^{-1}$ to $250 \mathrm{mg} \mathrm{L}^{-1}$ to verify the performance of the denitri- fying granular sludge at the influent $\mathrm{C} / \mathrm{N}$ ratio of 5:1. The HRT of the three reactors all remained at $3.5 \mathrm{~h}$ throughout examination period. The reactors were operated at room temperature $\left(16-25^{\circ} \mathrm{C}\right)$.

\subsection{Extraction of signal molecules}

The extraction of AHLs was conducted following a previously published method [17] with modifications. Twenty $\mathrm{mL}$ of the mixture containing $10 \mathrm{~mL}$ sludge and $10 \mathrm{~mL}$ water was crushed by an ultrasonic cell crusher and centrifuged at $14800 \mathrm{~g}$ for $10 \mathrm{~min}$. The supernatants were then harvested and filtered through a $0.22 \mu \mathrm{m}$ syringe filter. Next, $10 \mathrm{~mL}$ of the above sample was extracted with an equivalent volume of ethyl acetate. This mixture was shaken vigorously using a separating funnel and then stand still for five minutes, and the phases were allowed to separate [18]. The combined ethyl acetate fractions were evaporated to complete dryness and re-dissolved in $2 \mathrm{~mL}$ of $100 \%$ methanol for subsequent analysis.

\subsection{Signal molecules extraction and measurement}

All samples were chromatographed with an Agilent Acquity UPLC (Agilent, USA) at a flow rate of $0.3 \mathrm{~mL} \mathrm{~min}^{-1}$. The column dimensions were $4.6 \times 5 \mathrm{~mm}$, and the column was filled with $\mathrm{BEH}$ C18 packing material with a $1.8 \mu \mathrm{m}$ particle size. The column was thermostated at $40{ }^{\circ} \mathrm{C}$ and the sample system was at $4{ }^{\circ} \mathrm{C}$. The mobile phase consisted of a linear gradient (70-90\%) of solvent B (methanol) and solvent A (water with $0.1 \%$ formic acid). The effluent had been ionized via electrospray ionization in positive mode and was analyzed using a multiple reactions-monitoring approach by Agilent 6430 B MS (Agilent, USA) [19]. Matrix-matched multiple reaction-monitoring experiments were conducted for four standard AHLs.

\subsection{Microbial analysis}

To reveal microbial characteristics, sludge samples were collected at initial and acclimatization periods (initial sludge: 0; acclimatization period sludge: 1, 2, and 3) for analysis via highthroughput sequencing. Total DNA were extracted for each sludge sample, using the E.Z.N.A. Soil DNA Kit (Omega, U.S.A.). The DNA samples were then pooled for further molecular analysis. The $341 \mathrm{~F}$ and $805 \mathrm{R}$ primers were used for PCR amplification. Four samples amplicons were combined, purified, and then sequenced on an Illumina MiSeq platform by Sangon Biotech (Shanghai) Co. Ltd. Reads containing one or moreambiguous bases ("N") wereremoved. Each sample was then overlapped to assemble V3-V4 tags of the 16S rRNA geneusingSeqPrep for paired-end reads. Chimera sequences were removed via UCHIME. After quality filtration, between 23337 and 71463 sequences were obtained per sample. Using Uclust analysis, sequences with $>97 \%$ similarity were clustered to form operation taxonomic units (OTUs). Additionally, the a-diversity, including rarefaction curves, Chao species richness index, Shannon and Coverage index, was calculated by Mothur software.

\subsection{Other analysis methods}

The chemical oxygen demand (COD), MLSS and MLVSS were measured using standard methods [20]. For the denitrification experiments, samples were with-drawn at regular intervals and centrifuged at $6570 \mathrm{~g}$ for $10 \mathrm{~min}$ each to remove insoluble particles. The NO-3-N, NO-2-N, and total nitrogen (TN) concentrations in the supernatant were measured colourimetrically with UV spectrophotometry (Tianmei, UV2600, UV/Vis spectrophotometer, China) according to standard methods [21]. The average particle size of denitrifying granular sludge was measured with the sieve 
Table 1

Operating conditions of three reactors during two experimental periods.

\begin{tabular}{|c|c|c|c|c|c|}
\hline \multirow[t]{2}{*}{ Reactor } & \multicolumn{2}{|l|}{ Acclimation period $(0-18 d)$} & \multicolumn{2}{|c|}{ Examination period (19-30d) } & \multirow[t]{2}{*}{ Temperature } \\
\hline & HRT (h) & $\begin{array}{l}\text { NO- 3-N and CODload } \\
\left(\mathrm{mg} \mathrm{l}^{-1}\right)(\text { Constant })\end{array}$ & HRT (h) & $\begin{array}{l}\text { NO- 3-N and COD load } \\
\left(\mathrm{mg} \mathrm{l}^{-1}\right) \text { (Three days to } \\
\text { upgrade once) }\end{array}$ & \\
\hline $\mathrm{R}_{\mathrm{C}}$ & C-HRT (3.5h constant) & 50 and 250 & C-HRT (3.5 h) & $100-250$ and $500-1250$ & $16-25^{\circ} \mathrm{C}$ \\
\hline $\mathrm{R}_{\mathrm{DF}}$ & DF-HRT ( 3.5 and $1.75 \mathrm{~h}$ change once a day) & 50 and 250 & C-HRT (3.5h) & $100-250$ and $500-1250$ & $16-25^{\circ} \mathrm{C}$ \\
\hline $\mathrm{R}_{\mathrm{UF}}$ & UF-HRT ( 3.5 and $7 \mathrm{~h}$ change once a day) & 50 and 250 & C-HRT (3.5h) & $100-250$ and $500-1250$ & $16-25^{\circ} \mathrm{C}$ \\
\hline
\end{tabular}

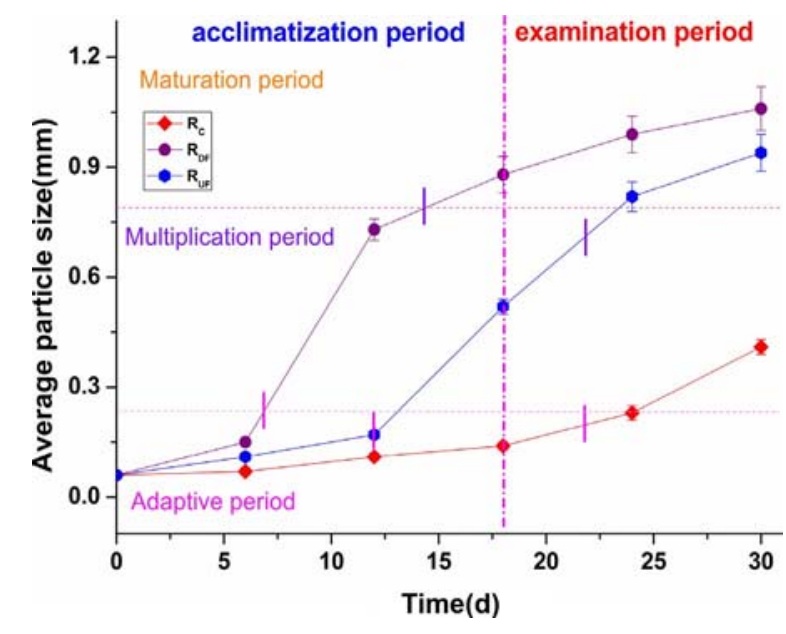

Fig. 1. Average particle size of denitrifying granular sludge from $R_{C}, R_{D F}$ and $R_{U F}$.

method. Heat EPS extraction procedures [15] were used and extracellular polysaccharides (PS) and extracellular proteins (PN) were assayed by the anthrone-sulfuric acid method [22] and Coomassie brilliantblueassay [23], respectively. ThePS and PN weremeasured by the UV spectrophotometry (Tianmei, UV2600, UV/Vis spectrophotometer, China). Total EPS was expressed as total organic carbon (TOC), which was measured by a TOC meter. All measured results were normalized by TOC of EPS tofacilitatecomparison. The above experiment (except COD, NO-3-N and TN) is replicates three times and the standard deviation method was used to determine the spread.

\section{Results and discussion}

\subsection{Effect of fluctuation HRT on the characteristics of denitrifying granular sludge}

\subsubsection{Denitrifying sludgegranulation}

The granulation processes within $\mathrm{R}_{\mathrm{C}}, \mathrm{R}_{\mathrm{DF}}$ and $\mathrm{R}_{\mathrm{UF}}$ were divided into three periods (i.e., the adaptive, the multiplication, and the maturation periods) according to different observed morphologies and physical characteristics [24].

Adaptive period: Initially, the seed sludge in $\mathrm{R}_{\mathrm{C}}, \mathrm{R}_{\mathrm{DF}}$, and $\mathrm{R}_{\mathrm{UF}}$ was black in color and flocculent in visual image. The average particle size of the seed sludge was $0.06 \pm 0.01 \mathrm{~mm}$ (Fig. 1). After acclimation of 22 days, yellowish fine granules formed at the walls of $R_{C}$ (C-HRT). The average particle size of the sludge in $\mathrm{R}_{\mathrm{C}}$ varied from $0.06 \pm 0.01 \mathrm{~mm}$ to $0.23 \pm 0.02 \mathrm{~mm}$ during an acclimation of 24 days. In comparison, the sludge in $\mathrm{R}_{\mathrm{UF}}$ (UF-HRT) formed tiny aggregates (aggregates and granules both refer to granulation) after an acclimation of 12 days at an $\mathrm{C} / \mathrm{N}$ ratio of 5:1; here, the average particle size varied from $0.06 \pm 0.01 \mathrm{~mm}$ to $0.17 \pm 0.01 \mathrm{~mm}$. Notably, the sludge in $\mathrm{R}_{\mathrm{DF}}$ (DF-HRT) developed numerous tiny aggregates on day 7 , and after just 6 days of acclimation the average particle size of sludge in $R_{D F}$ varied from $0.06 \pm 0.01 \mathrm{~mm}$ to $0.15 \pm 0.01 \mathrm{~mm}$.
Compare with $\mathrm{R}_{\mathrm{C}}$, the average particle size of denitrifying granular sludge was accelerated by $68 \%$ and $45 \%$ as a result of the DF-HRT and UF-HRT application, respectively. The fact that granules had formed earlier in $R_{D F}$ could be attributed to a higher hydraulic shear force, and in $\mathrm{R}_{\mathrm{UF}}$ could be attributed to appropriately reduce influent organic matter content, these two special condition could promote biomass aggregation, which took place at a much shorter period. These studies were consistent with the results of earlier studies $[15,25]$. These results indicate that the use of both UF-HRT and DF-HRT strategies could shorten the adaptive period compared to the C-HRT strategy.

Multiplication period: Although the average particle size of the sludge increased in all three reactors during this period, the rates of increase remained different among the three reactors. The sludge in $R_{D F}$ and $R_{U F}$ had achieved complete granulation (average particle size greater than $0.8 \mathrm{~mm}$ ) on days 22 and 14, respectively. However, the average particle size of the sludge in $\mathrm{R}_{\mathrm{C}}$ varied from $0.23 \pm 0.02 \mathrm{~mm}$ to $0.41 \underline{\theta} .02 \mathrm{~mm}$ from day 24 to day 30 . The average particle size of sludge was increased by $0.18 \mathrm{~mm}$ as a result of C-HRT application. However, the average particle size of the sludge increased by 0.58 and $0.35 \mathrm{~mm}$ as a result of DF-HRT and UF-HRT applications, respectively after 6 days of acclimation. These resultsindicate that the use of UF-HRT and DF-HRT strategies could accelerate the multiplication period compared to using the C-HRT strategy.

Maturation period: The maturation period of $R_{D F}$ and $R_{U F}$ in this experiment lasted for 16 and 8 days, respectively. The average particle size of sludge in $R_{D F}$ and $R_{U F}$ had slowly increased during this period. The shear force can only result in slight changes in visual image. However, the $\mathrm{R}_{\mathrm{C}}$ sludge has not undergone a multiplication period due to the operating time limit.

These results indicated that using UF-HRT and DF-HRT strategies promoted the formation of denitrifying granular sludge.

\subsubsection{Effect of fluctuation HRT on EPS of denitrifying granular sludge}

EPS are important for maintaining a rich matrix structure and stability of denitrifying granular sludge by altering the adhesion ability of the bacterial surface [14]. EPS detection was achieved by measuring proteins (PN), polysaccharides (PS), and humic acid of the denitrifying granular sludge during the 30 days of operation of the three UASB reactors as shown in Fig. 2. The total EPS content of all three reactors did not differ notably, however, significant differences were obtained for PN and PS. In $R_{C}$, the PN

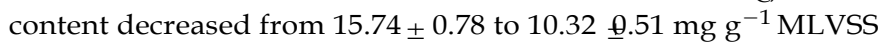
during the acclimatization period. However, an increase of PN content was observed in $\mathrm{R}_{\mathrm{DF}}$ during theacclimatization period, whereit increased from $15.74 \pm 0.78$ to $19.61 \pm 0.98 \mathrm{mg} \mathrm{g}^{-1}$ MLVSS. During the acclimatization period, the PN content was lowest in RUF among all three reactors, and the content decreased from $15.74 \pm 0.78$ to $7.56 \pm 0.37 \mathrm{mg} \mathrm{g}^{-1}$ MLVSS. As shown in Table 2. The MLVSS varied from $8.9 \pm 0.44$ to $13.6 \pm 0.68$, as well as $13.2 \pm 0.66$ and $14.8 \pm 0.74 \mathrm{mg} \mathrm{L}^{-1}$ during the acclimatization period, eventually varying to $16.4 \pm 0.82,17.9 \pm 0.89$, and $19.6 \pm 0.98 \mathrm{mg} \mathrm{L}^{-1}$ for $R_{C}, R_{D F}$ and $R_{U F}$, respectively. The VSS/SS varied from an initial 0.644 for 
Table 2

Effects of fluctuating HRT on the characteristics of denitrifying granular sludge.

\begin{tabular}{|c|c|c|c|c|c|c|c|}
\hline \multirow[t]{2}{*}{ Sludge characteristics } & \multirow[t]{2}{*}{ Reactor } & \multicolumn{6}{|l|}{ Time(d) } \\
\hline & & 0 & 6 & 12 & 18 & 24 & 30 \\
\hline \multirow{3}{*}{$\operatorname{MLSS}\left(\mathrm{g} \mathrm{L}^{-1}\right)$} & $\mathrm{R}_{\mathrm{C}}$ & $13.8 \pm 0.6$ & $22.6 \pm 1.1$ & $18.2 \pm 0.9$ & $16.5 \pm 0.8$ & $28.9 \pm 1.4$ & $24.5 \pm 1.2$ \\
\hline & $\mathrm{R}_{\mathrm{DF}}$ & $13.8 \pm 0.6$ & $22.6 \pm 1.1$ & $19.5 \pm 0.9$ & $13.9 \pm 0.6$ & $16.8 \pm 0.8$ & $27.7 \pm 1.3$ \\
\hline & $\mathrm{R}_{\mathrm{UF}}$ & $13.8 \pm 0.6$ & $17.1 \pm 0.8$ & $19.7 \pm 0.9$ & $19.6 \pm 0.9$ & $25.1 \pm 1.2$ & $31.3 \pm 1.5$ \\
\hline \multirow[t]{3}{*}{$\operatorname{MLVSS}\left(\mathrm{g} \mathrm{L}^{-1}\right)$} & $\mathrm{R}_{\mathrm{C}}$ & $8.9 \pm 0.4$ & $19.7 \pm 0.9$ & $18.1 \pm 0.9$ & $13.6 \pm 0.6$ & $19.8 \pm 0.9$ & $16.4 \pm 0.8$ \\
\hline & $\mathrm{R}_{\mathrm{DF}}$ & $8.9 \pm 0.4$ & $19.1 \pm 0.9$ & $19.4 \pm 0.9$ & $13.2 \pm 0.6$ & $13.5 \pm 0.6$ & $17.9 \pm 0.8$ \\
\hline & $\mathrm{R}_{\mathrm{UF}}$ & $8.9 \pm 0.4$ & $13.5 \pm 0.6$ & $14.9 \pm 0.7$ & $14.8 \pm 0.7$ & $18.1 \pm 0.9$ & $19.6 \pm 0.9$ \\
\hline \multirow[t]{3}{*}{ VSS/SS } & $\mathrm{R}_{\mathrm{C}}$ & 0.644 & 0.871 & 0.994 & 0.824 & 0.685 & 0.669 \\
\hline & $\mathrm{R}_{\mathrm{DF}}$ & 0.644 & 0.841 & 0.994 & 0.949 & 0.803 & 0.646 \\
\hline & $\mathrm{R}_{\mathrm{UF}}$ & 0.644 & 0.789 & 0.756 & 0.755 & 0.721 & 0.626 \\
\hline
\end{tabular}

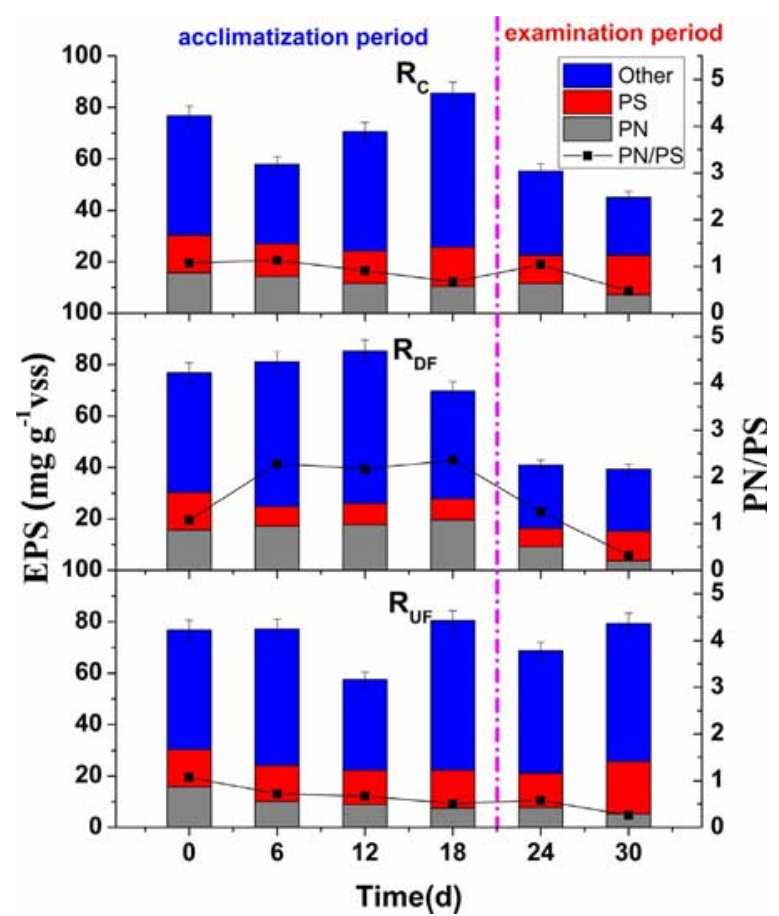

Fig. 2. Change in the EPS during the granulation process: $R_{C}, R_{D F}$ and $R_{U F}$.

all reactors to $0.824,0.949$, and 0.755 during the acclimatization period, eventually varying to $0.669,0.646$ and 0.626 for $R_{C}, R_{D F}$, and $R_{U F}$, respectively.

Liu et al. [26] reported that the formation of granules may mainly depend on the kernel protein within the granular sludge. The increase of PN content can effectively change cellsurface hydrophobicity, which is beneficial to the formation of granular sludge [27] In this study, the increased $\mathrm{PN}$ production of $\mathrm{R}_{\mathrm{DF}}$ could be attributed to the disturbance stimulate achieved by the DF-HRT condition. Xue el al. [25] reported that low hydraulic shear force might stimulate lower PN production. Niu el al. [15] reported that microbes could use proteins of EPS as carbon sources to survive periods with scarce carbon source availability. Correspondingly, the decreased PN concentration in RUF could also be attributed to both low hydraulic shear force and microbial utilization. Although the PN production in RUF was lower, our previous study suggested that appropriately reducing the influent organic matter could promote biomass aggregation because it stimulates starvation. This could explain that the denitrifying granular sludge formation was faster in $R_{U F}$ than in $R_{C}$. In summary, the possible explanation for the above phenomena is the existence of extreme disturbance in the external environment during the granulation process. This disturbance provides more opportunities for microbial contact and therefore stimulated components of EPS secretions during the DF-HRT condition. Compared to the C-HRT condition, the disturbance also provides more opportunities for microbial contact in the UF-HRT condition, and this condition also inhibited the growth of microorganisms.

\subsection{Effect of fluctuation HRT on UASB reactor performances}

The performance of UASB reactors for denitrification under fluctuation HRT conditions was investigated. In this study, thenitrogen and CODremovalefficiencies (\%) wereused todescribetheremoval characteristics of the three reactors during the entire operation. Fig. 3 shows the changes in reactor performance in terms of NO-3-N removal, TN removal and COD removal during two periods. During the acclimatization period (after three days of acclimatization), the NO-3-N and COD concentrations in $\mathrm{R}_{\mathrm{C}}$ were below $3.6 \mathrm{mg} \mathrm{L}^{-1}$ and $38.1 \mathrm{mg} \mathrm{L}^{-1}$ and maintained a steady state from days $4-18$, suggesting that the sludge contained adequate denitrifying bacteria to remove the nitrogen after an acclimatization of three days. The COD, NO-3-N, and TN removal efficiencies in $\mathrm{R}_{\mathrm{C}}$ remained above $84 \%, 92 \%$ and $73 \%$ between days 4 and 18 . Compared to $\mathrm{R}_{\mathrm{C}}$, after four days of acclimatization, the NO-3-N and COD concentrations in $R_{D F}$ and $R_{U F}$ were below $6.2 \mathrm{mg} \mathrm{L}^{-1}$ and $36.6 \mathrm{mg} \mathrm{L}^{-1}$ and maintained at a steady state from days 5-18, the COD, NO- 3-N, and TN removal efficiencies remained above $87 \%, 93 \%$, and $71 \%$ for $\mathrm{R}_{\mathrm{DF}}$ and above $85 \%, 87 \%$, and $71 \%$ for $\mathrm{R}_{\mathrm{UF}}$, respectively. These results indicated that the impact on reactor performance was negligible whether the DF-HRT or UF-HRT strategies were utilized. During the examination period, the COD, NO- 3-N, and TN removal efficiencies remained above $95 \%, 97 \%$, and $96 \%$ for $\mathrm{R}_{\mathrm{DF}}$ and $86 \%, 92 \%$, and $87 \%$ for $R_{U F}$ throughout the entire phase. Comparatively, when influent COD and NO-3-N concentrations increased to $1250 \mathrm{mg} \mathrm{L}^{-1}$ and $250 \mathrm{mg} \mathrm{L}^{-1}$ in $\mathrm{R}_{\mathrm{C}}$, the COD, NO- 3-N, and TN removal efficiencies were declined to $85 \%, 81 \%$, and $71 \%$, respectively.

These results showed that using UF-HRT and DF-HRT strategies led to the development of denitrifying granular sludge with a better performance than using C-HRT strategy.

\subsection{Effect of fluctuation HRT on AHLs produced by microorganisms}

Because QS-regulated bacteria released AHLs into their surroundings, it was necessary to detect AHLs in the reactors. As shown in Fig. 4, four types of AHLs were extracted from the reactors via UPLC-MS. Initially, the reactors contained small amounts of AHLs due to a shortage of Gram-negative bacteria. However, after 18 days of acclimatization, the AHLs contents were markedly different between the three reactors. In $R_{C}$ and $R_{U F}$, although the concentrations of all four types of AHLs (C6-HSL, C8-HSL, 3-oxo-C8-HSL, and C10-HSL) in two reactors presented an increasing trend, however, the concentrations of all fourtypes of AHLs remained different between $R_{C}$ and $R_{U F}$. The concen- 

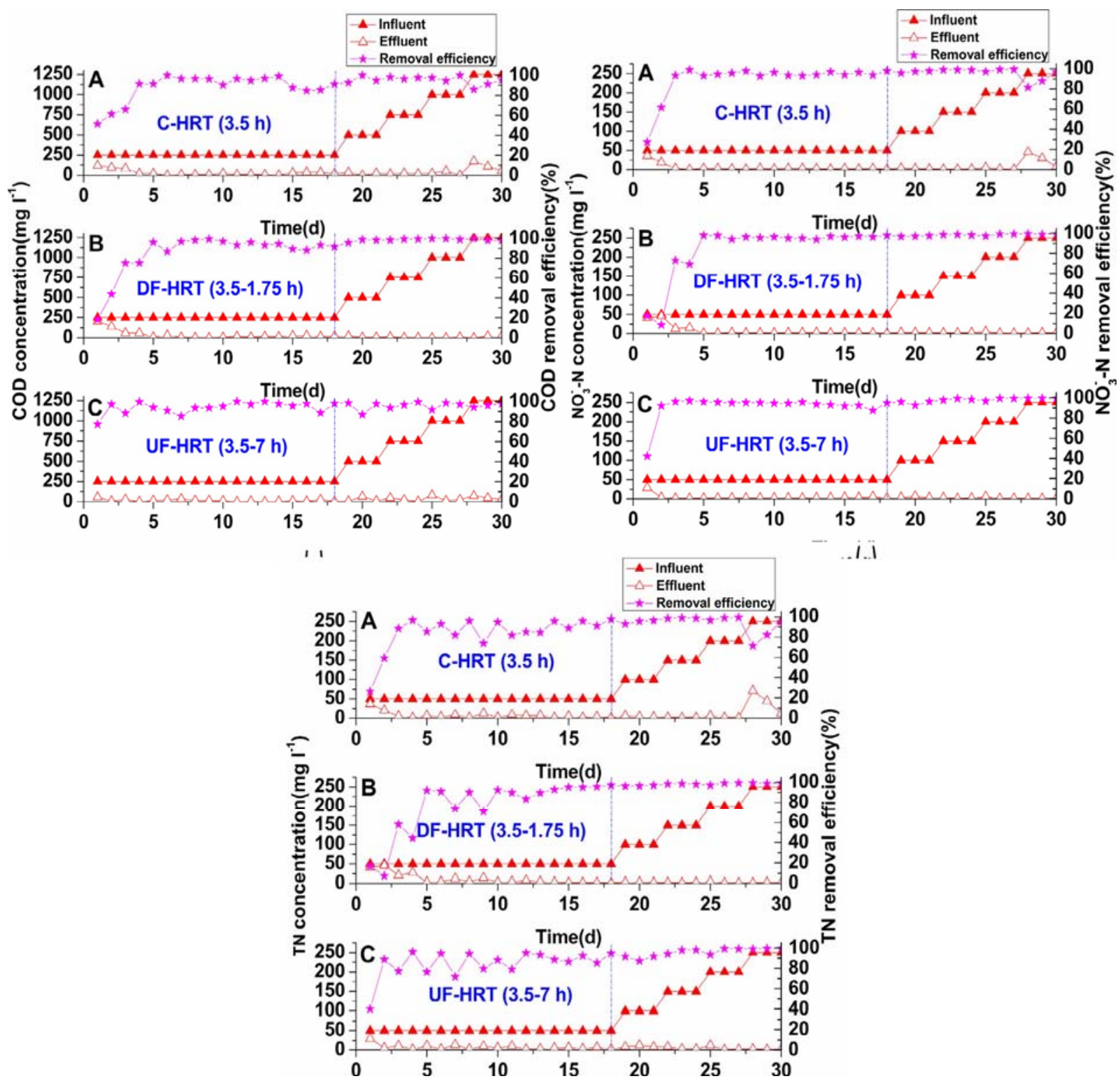

Fig. 3. Performance of COD, NO- $3-N$ and TN removal efficiency in (a) $R_{C}$, (b) $R_{D F}$ and (c) $R_{U F}$

trations of four AHLs in $\mathrm{R}_{\mathrm{C}}$ increased from $0.58_{ \pm} 0.02$ (C6-HSL), $0.68+0.03$ (C8-HSL), $0.03 \pm 0.01$ (3-oxo-C 8 -HSL), and $0.32 \pm 0.01$ (C10-HSL) $\mu \mathrm{g} \mathrm{g}^{-1}$ MLVSS to $1.6 \underline{6} 0.08,0.94_{ \pm} 0.04,0.43_{ \pm} 0.02$ and $1.07 \pm 0.05 \mu \mathrm{g} \mathrm{g}^{-1}$ MLVSS, respectively. With the exception of C8-HSL, all values eventually increased more than three-fold after 18 days of operation. Compared to $R_{C}$, the concentrations of all four AHLs in $\mathrm{R}_{\mathrm{UF}}$ increased from $0.58_{ \pm} 0.02$ (C6-HSL), $0.68 \pm 0.03$ (C8-HSL), $0.03 \pm 0.01$ (3-oxo-C8-HSL), and $0.32 \pm 0.01$ (C10-HSL) $\mu \mathrm{gg}^{-1}$ MLVSS to $3.63_{\Perp} \quad 0.18,2.04_{ \pm} 0.11,1.31_{ \pm} 0.06$ and 2.51 Q.12 $\mathrm{gg} \mathrm{g}^{-1}$ MLVSS, respectively. With the exception of C8HSL, all values eventually increased more than seven-fold. The increases of the AHLs concentrations were much higher in $R_{D F}$ than in $R_{C}$. In addition, the concentrations of all four AHLs in $R_{D F}$ first increased and then decreased during the 18 days of operation. The AHLs concentrations in $\mathrm{R}_{\mathrm{DF}}$ increased from $0.58_{ \pm} 0.02$ (C6-HSL), $0.68 \underline{0} 03$ (C8-HSL), $0.030 . \underline{1}$ (3-oxo-C8-HSL) and $0.320 .01_{ \pm}(\mathrm{C} 10-$ HSL) $\mu \mathrm{g} \mathrm{g}^{-1}$ MLVSS to $2.74 \quad 0 . \underline{13}, 1.230 .0 \underline{6}, 1.190 .0 \underline{5}$, and $2.010 .11 \mu \mathrm{g} \mathrm{g}^{-1}$ MLVSS, respectively, after a mere six days of operation. Afterwards, the AHLs remained relatively stable from days 6-12; finally, the AHLs concentrations decreased to
$1.55 \pm 0.07,1.07 \pm 0.05,0.76 \underline{\oplus} .03$, and $0.93 \underline{\Theta} .04 \mu \mathrm{g} \mathrm{g}^{-1}$ MLVSS on day 18. A detailed comparison of AHLs concentrations (Fig. 4) and granulation processes (Fig. 1) shows that the increase of AHLs concentrations in all three reactors was accompanied by the formation of denitrifying granules. In the process of denitrifying granular sludge formation, microbes produced excessive amounts of AHLs. This experimental observation indicates that an increase in AHLs concentrations is related to the formation of denitrifying granular sludge. The results of this experiment agreed with previously conducted studies [28]. During the examination period, all four AHLsconcentrations of three reactors showed a steady trend. However, the AHLs concentrations in $R_{D F}$ and $R_{U F}$ were much higher than in $R_{C}$, and the AHLs concentrations in $R_{D F}$ were much higher than in $\mathrm{R}_{\mathrm{UF}}$. Hu et al. [13] and Li et al. [29] reported that QS can severely affect reactor performance, which indicated that higher AHLs concentrations would be beneficial for the removal of nitrogen and COD. This explains why the $\mathrm{R}_{\mathrm{DF}}$ and $\mathrm{R}_{\mathrm{UF}}$ nitrogen removal performance was higher than that of $R_{C}$ during this period. 


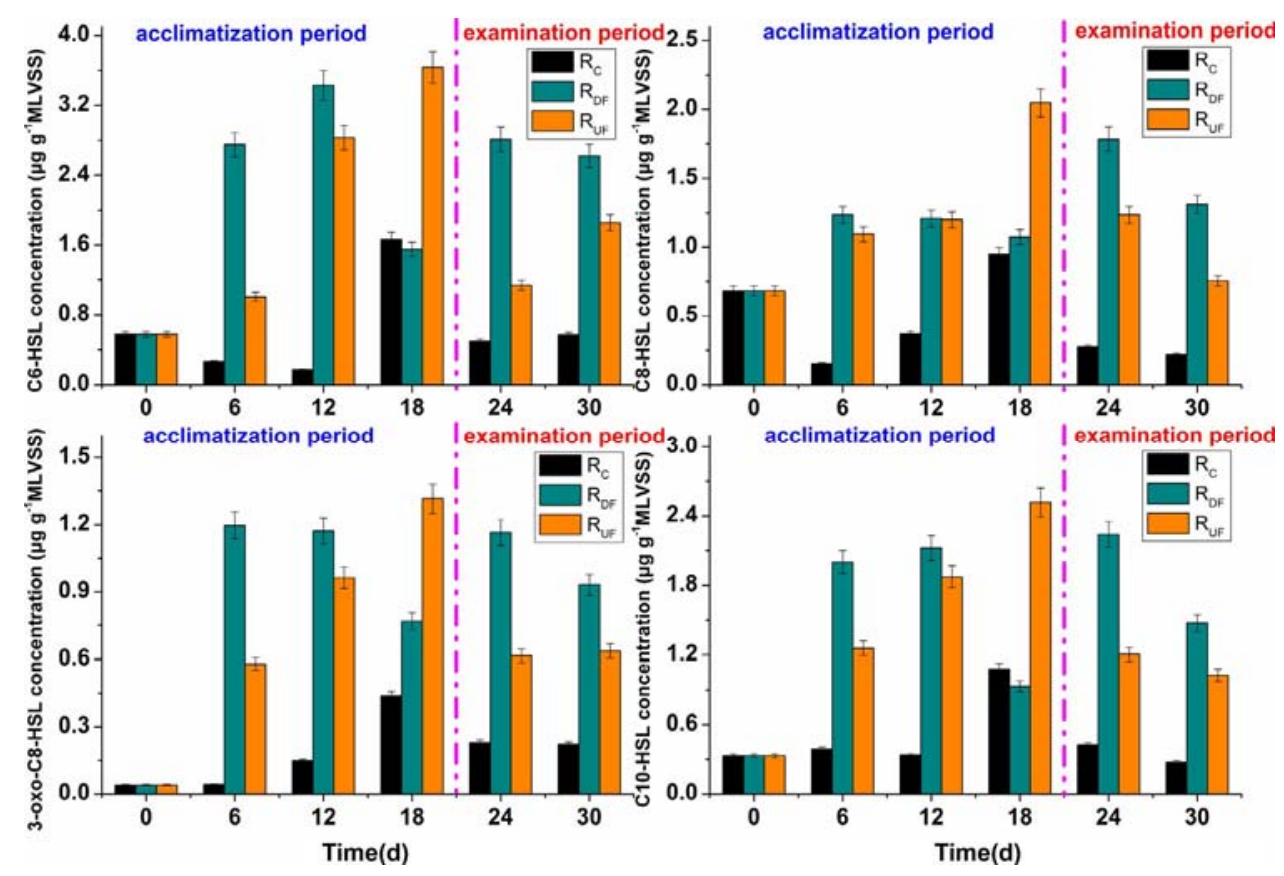

Fig. 4. Four AHLs in sludge samples of $R_{C}, R_{D F}$ and $R_{U F}$.

Table 3

Numbers of Seq num and OTUs, Good's coverage, and Chao1 and Shannon for al three UASB reactors at different periods: (0) Seed sludge; (1) acclimatization period after $R_{C} ;(2)$ acclimatization period after $R_{D F}$; (3) acclimatization period after $R_{U F}$.

\begin{tabular}{llllll}
\hline Sample & Seqnum & OTUs & Shannon & Coverage & Chao1_index \\
\hline 0 & 23337 & 1663 & 3.06 & 0.9421 & 10854 \\
1 & 57630 & 4078 & 4.85 & 0.9448 & 29590 \\
2 & 52030 & 3992 & 5.06 & 0.9366 & 31855 \\
3 & 71463 & 4785 & 4.94 & 0.9476 & 31545 \\
\hline
\end{tabular}

\subsection{Microbial communities}

Since using the fluctuation HRT strategy differ notably altered the bioreactor nitrogen removal efficiency, also promoting the formation of denitrifying granular sludge, we analyzed its effects on microbialcommunities.

As shown in Table 3, the DNA samples for microbial analysis had 23337-71463 sequences after sequence data processing. Using double-ended sequencing, each measuring $300 \mathrm{bp}$, the positive sequencing data is $R 1$, reverse sequencing data is $R 2$. The quality value Q20 of R1 is 95.52, the quality value Q20 of R2 is 77.26, and the quality value Q20 of average is 86.39. The Chao1 index showed an increasing trend from 0 to 1,2 , and 3 , indicating that the number of bacterial species continuously increased in the reactors. The good's coverage ranged between $93.66 \%$ and $94.47 \%$, suggesting that the microbial diversity of the bioreactor was well represented by constructed sequence libraries. The highest diversity (Shannon 5.06) was found in $\mathrm{R}_{\mathrm{DF}}$. The results of the present study indicate that using DF-HRT and UF-HRT strategies increases species richness.

Fig. 5 shows relative abundances of dominant genera for each sample. In the inoculated sludge, the dominant genera were heterotrophic bacteria, such as Ferruginibacter (15.09\%). After 18 days of operation, the microbial species and biodiversity considerably changed, and the microbial community had a strong distinction among the three reactors. In $R_{C}$, the dominant genus $(>4 \%)$ were Methyloversatilis, Terrimonas, and Ferruginibacter, which comprised $19.18 \%, 5.43 \%$, and $4.36 \%$ of sequences, respectively. Other genera were all present in minor components at no more than $4 \%$.
Methyloversatilis have so far been identified in various methanolfeeding denitrification systems [25,30]. Terrimonas is a genusfirst reported in 2006, and identified in various methanol-feeding denitrification systems; however, clarifying their function requires further investigation [30]. Compare with inoculated sludge, in the $\mathrm{R}_{\mathrm{C}}$ after 18 days of operation, Ferruginibacter reduced from $15.09 \%$ to $4.36 \%$ due to a drastic change in the environmental condition from anaerobic digestion to denitrification. The decrease of the population of these taxa was probably due to a lack of substrates during the denitrification process. In contrast, $R_{D F}$ and $R_{U F}$ experienced extensive microbial evolution. In $\mathrm{R}_{\mathrm{DF}}$, the dominant genus (>4\%) were Methyloversatilis, Simplicispira, Aeromonas, Pseudomonas, and Clostridium sensu stricto, which comprised $35.49 \%$, $6.12 \%, 5.84 \%, 5.71 \%$, and $4.03 \%$, respectively. Compared with the proportion of the genus in $\mathrm{R}_{\mathrm{C}}$, the proportion of the genus Ferruginibacter $(1.9 \%)$ in $\mathrm{R}_{\mathrm{DF}}$ was less than $2.46 \%$, but the proportion of the genus Methyloversatilis in $\mathrm{R}_{\mathrm{DF}}$ was more than $16.31 \%$. Furthermore, the proportion of the genus Terrimonas $(2.69 \%)$ in $\mathrm{R}_{\mathrm{DF}}$ was less than $2.74 \%$. Aeromonas and Simplicispira are two denitrifiers that belong to the Gram-negative bacteria and could utilize nitrates and oxygen as electron acceptors [30]. Pseudomonas is a denitrifying bacteria, which maintains the aerobic denitrificans in methanol-fed denitrifying systems, thus achieving continuous nitrate removal during transient oxidative conditions [30]. Clostridium is a genus of Gram-positive bacteria, which are obligate anaerobes that are capable of producing endospores. These were first identified in various methanol-feeding denitrification systems, and clarifying their functions also requires further investigation. Ferruginibacter and Terrimonas were reduced under the DF-HRT condition. The results showed that the DF-HRT condition could accelerate the reduction of non-denitrifiers (e.g., Ferruginibacter and Terrimonas), while the DF-HRT condition was beneficial for denitrifier enrichment (e.g., enriching Methyloversatilis, Simplicispira,Aeromonas and Pseudomonas). In RUF, the dominant genus (>4\%) were Methylotenera and Methyloversatilis, which comprised $11.79 \%$ and $10.36 \%$, respectively. This result differs from a reported study that used an activated sludge system, which showed that extended HRT reduced microorganism diversity. This result agreed with previously reported data $[15,25]$, showing that low organic loading and 


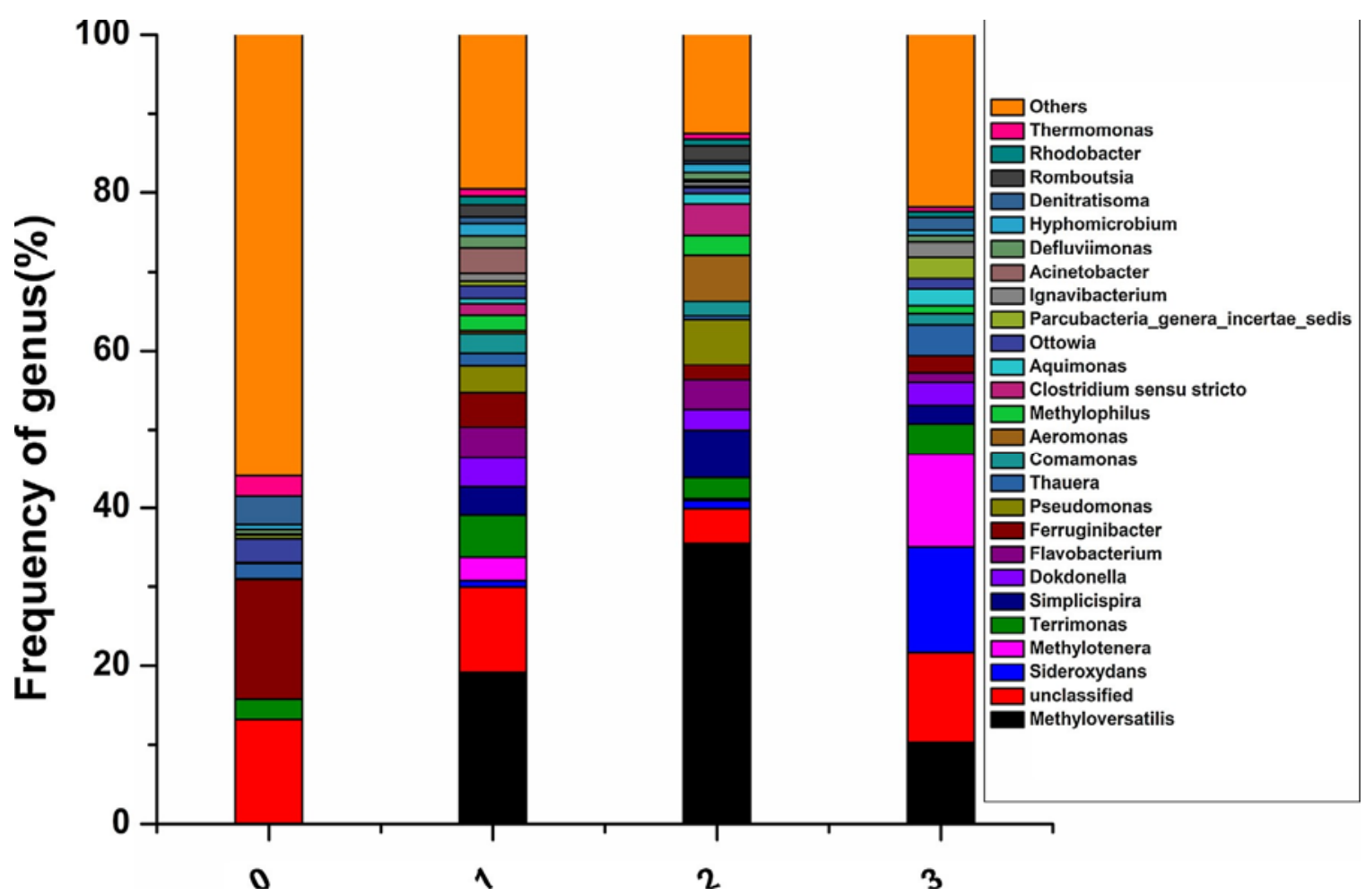

Fig. 5. Distributions in genus levels derived by high-throughput sequencing of bacterial $16 \mathrm{~S}$ rRNA in four samples: (0) Seed sludge, (1) acclimatization period after $R_{C}$, (2) acclimatization period after $R_{\mathrm{DF}}$, and (3) acclimatization period after $R_{\mathrm{UF}}$.

higher hydraulic shear force increased microbial diversity. Certain bacteria such as Aeromonas were only detected in $\mathrm{R}_{\mathrm{C}}$ and $\mathrm{R}_{\mathrm{DF}}$ during the acclimatization period. This suggested that the UF-HRT condition might inhibit the growth of Aeromonas, while a DF-HRT condition might stimulate the growth of Aeromonas.

\subsection{Mechanism of denitrifying sludge granulation using both DF-HRTandUF-HRTstrategies}

This study provides the first comprehensive report on the relationship between microbial community variation, AHLs variation, EPS characterization, and the performances of denitrifying granular sludge using both DF-HRT and UF-HRT strategies.

\subsubsection{Under the UF-HRT condition $\left(R_{U F}\right)$}

Microbial aggregates appeared in $R_{U F}$ on day 12 . On day 22, the sludge within $R_{U F}$ achieved complete granulation. As shown in Table 4. Compared to a previous study, the complete granulation time was delayed for two days compared to our previous study, which was keep ahead of the results found in other studies. Our previously study showed that appropriately reduced influent organic matter content and disturbance stimulated conditions could promote the formation of denitrifying granular sludge [15]. The UF-HRT condition could also provide the appropriately reduced influent organic matter content and disturbance stimulate conditions due to the specific characteristics of operation. Therefore, the mechanism from the aspect of QS for denitrifying sludge granulation via the UF-HRT strategy was similar to our previous studies. Nevertheless, since the hydraulic shear force plays an important role in the formation of denitrifying granular sludge, the UF-HRT condition provided a low hydraulic shear force due to the characteristics of operation. This reason may explain why the denitrifying granular sludge formation in $R_{U F}$ happened later than in previously studies.

\subsubsection{Under the DF-HRT condition $\left(R_{D F}\right)$}

Microbial aggregates appeared in $R_{D F}$ on day 7 and the sludge had achieved complete granulation on day 14. Compared to the previous study (as shown in Table 4), the activated sludge complete granulation time in $\mathrm{R}_{\mathrm{DF}}$ was keep ahead of other studies. The self-immobilization of bacteria into granules involves physical, chemical, and biological cell-to-cell interactions [31]. Based on the impact of operational parameters on the granulation processes in this study, a possible mechanism of denitrifying sludge granulation using the DF-HRT strategy, consideringQS, could beestimated as follows (Fig. 6): 1) the DF-HRT condition provides an intensified selection pressure, which changed the microbial community structure; 2) the changed microbial community structure could in turn promote the production of AHLs; 3) the AHLs molecules stimulate microbial PN secretion, thus possibly changing cell motility and biological cell-to-cell interactions, resulting in the formation of small aggregates; 4 ) bacteria continuously adhere onto the surface of aggregates and become increasingly compact; 5) microbial and physics forces (e.g., more PN production and higher hydraulic shear force) further stimulate both the integration and stabilization of granule formation toward a mature state; and 6) matured granules are regulated and shaped by shear forces.

\section{Conclusions}

Denitrifying granular sludge formation was accelerated through via DF-HRT strategy. The conclusion of this study wasas follows: (1) This study determined that microbial community, AHLs, EPS, and the denitrifying sludge granulation process were associated with each other; (2) Compared to the C-HRT strategy, activated sludge that had been cultivated with the DF-HRT strategy was observed to produce higher concentrations of AHLs, while increasing the total amount of PN of EPS; (3) The microbial community that was identified in three reactors emphasized that the DF-HRT and UF-HRT condition were more robust against fluctuations in nutrient load. 
The formation time of different granular sludge with different strategy.

\begin{tabular}{lllll}
\hline Reactor & Inoculated sludge & Granular sludge type & Complete granulation time (d) & Operation strategy \\
\hline SBR & Activated sludge & Aerobic & 48 & Alternating feed loadings \\
UASB & Activated sludge & Anaerobic & 58 & Reduce HRT \\
UASB & Activated sludge & Denitrification & 56 & Increase hydraulic shear force \\
UASB & Activated sludge & Denitrification & 20 & Semi-starvation fluctuation C/N ratio \\
UASB & Activated sludge & Denitrification & 14 & DF-HRT \\
\hline
\end{tabular}

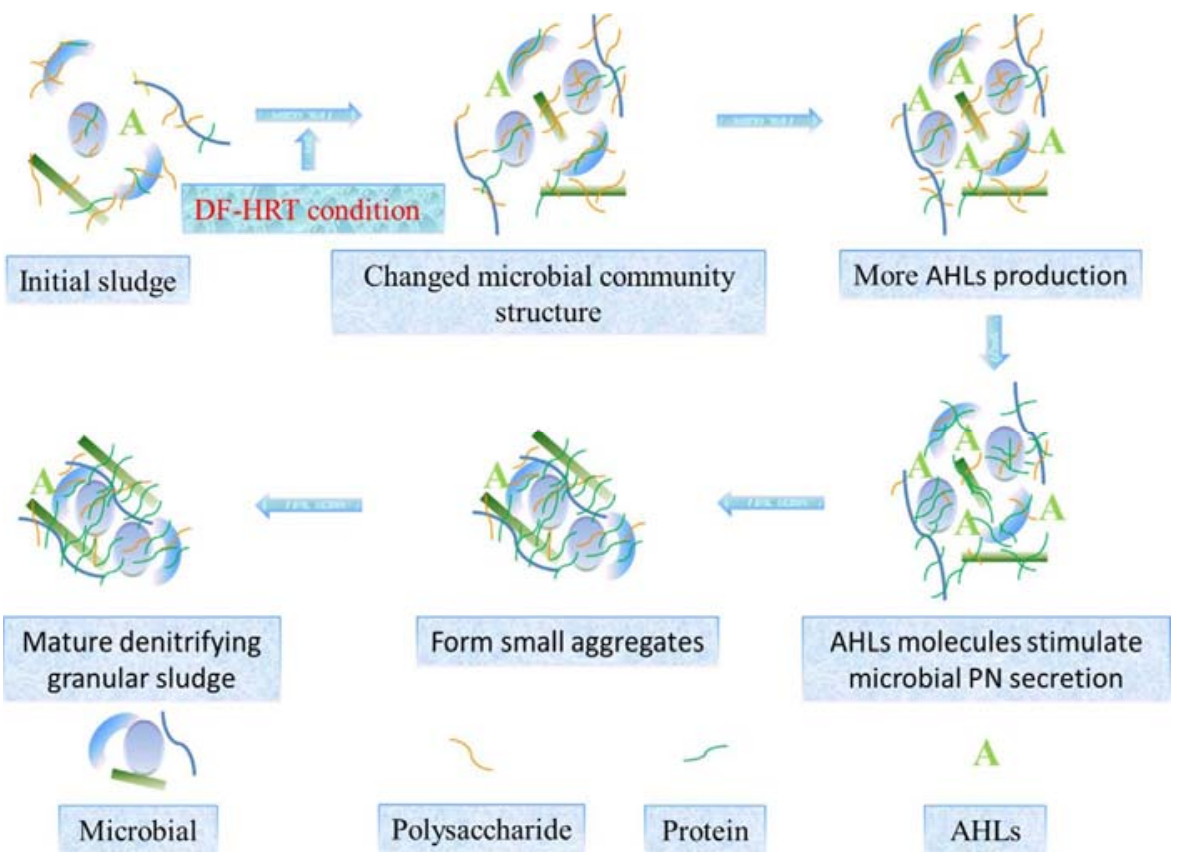

Fig. 6. Schematic of the denitrifying sludge granulation mechanism using the DF-HRT strategy and controlled via quorum sensing (QS) system.

Finally, compared with the traditional cultivate methods [25], these results showed the feasibility of a cheap and fast ways to cultivate denitrifying granular sludge for the future implementation for the treatment of actual wastewater.

\section{Acknowledgements}

This study was supported by the National Natural Science Foundation of China (Grant No. 51678387), Key project of Tianjin Natural Science Foundation (17JCZDJC39300) and the Science Reseach Program of High Level Talents in Hebei Universities (Grant No. GCC2014045, China.).

\section{References}

[1] H.S. Li, et al., Nitrogen and carbon removal from Fenton-treated leachate by denitrification and biofiltration, Bioresour. Technol. 101 (20) (2010) 7736.

[2] R. Knowles, Denitrification, Microbiol. Rev. 46 (1) (1982) 43.

[3] H. Han, et al., Effect of COD level and HRT on microbial community in a yeast-predominant activated sludge system, Bioresour. Technol. 101 (10) (2010) 3463-3465.

[4] P. Sivagurunathan, et al., Effect of hydraulic retention time (HRT) on biohydrogen production from galactose in an up-flow anaerobic sludge blanket reactor, Int. J. Hydrogen Energy 41 (46) (2016) 21670-21677.

[5] E. Jeong, et al., Effects of the hydraulic retention time on the fouling characteristics of an anaerobic membrane bioreactor for treating acidifi ed wastewater, Desalin. Water Treat. 18 (1-3) (2010) 251-256.

[6] K. Muda, et al., The effect of hydraulic retention time on granular sludge biomass in treating textile wastewater, Water Res. 45 (16) (2011) 4711-4721.

[7] Y.Q. Liu, et al., Effects of hydraulic retention time on aerobic granulation and granule growth kinetics at steady state with a fast start-up strategy, Appl. Microbiol. Biotechnol. 100 (1) (2016) 469.

[8] D.H. Kim, et al., Effect of hydraulic retention time on lactic acid production and granulation in an up-flow anaerobic sludge blanket reactor, Bioresour. Technol. 165 (8) (2014) 158-161.
J.H. Tay, Q.S. Liu, Y. Liu, The effects of shear force on the formation, structure and metabolism of aerobic granules, Appl. Microbiol. Biotechnol. 57 (1-2) (2001) 227-233.

[10] Y.He, Y. Wang, X. Song, High-effective denitrification of low C/N wastewater by combined constructed wetland and biofilm-electrode reactor (CW-BER) Bioresour. Technol. 203 (2016) 245-251.

[11] Z.C. Wang, et al., Effect of hydraulic retention time on performance of an anoxic-aerobic sequencing batch reactor treating saline wastewater, Int. J. Environ. Sci. Technol. 12 (6) (2015) 2043-2054

[12] Z.P. Zhang, D.T. Liang, W.J. Jiang, Effect of hydraulic retention time on biohydrogen production and anaerobic microbial community, Process Biochem. 41 (10) (2006) 2118-2123.

[13] $\mathrm{H}$. Hu, et al., Biofilm activity and sludge characteristics affected by exogenous $\mathrm{N}$-acyl homoserine lactones in biofilm reactors, Bioresour. Technol. 211 (2016) 339.

[14] S. Sun, et al., The role of autoinducer-2 in aerobic granulation using alternating feed loadings strategy, Bioresour. Technol. 201 (2016) 58-64.

[15] W. Niu, et al., Rapid start-up of denitrifying granular sludge by dosing with semi-starvation fluctuation C/N ratio strategy, Bioresour. Technol. 241 (2017) 945-950.

[16] Y.C. Yang, et al., Accelerated aerobic granulation using alternating feed loadings: alginate-like exopolysaccharides, Bioresour. Technol. 171 (2014) 360-366.

[17] H. Feng, et al., Where are signal molecules likely to be located in anaerobic granular sludge? Water Res. 50 (2014) 1-9.

[18] L. Ravn, et al., Methods for detecting acylated homoserine lactones produced by Gram-negative bacteria and their application in studies of AHL-production kinetics, J. Microbiol. Methods 44 (3) (2001) 239-251.

[19] A.W. Decho, et al., Autoinducers extracted from microbial mats reveal a surprising diversity of $\mathrm{N}$-acylhomoserine lactones (AHLs) and abundance changes that may relate to diel pH, Environ. Microbiol. 11 (2) (2009) 409-420.

[20] W.G. Walter, APHA standard methods for the examination of water and wastewater, Freshwater Sci. 56 (3) (1998) 387.

[21] $\mathrm{N}^{\circ}$, Standard Methods for the Examination of Water and Wastewater, 21st Edition. Journal - American Water Works Association, (1) (2006) 130.

[22] A. Gaudy, Colorimetric determination of protein and carbohydrate, Ind. Water Wastes 7 (1) (1962) 17-22.

[23] B. Fr/Olund, T. Griebe, P.H. Nielsen, Enzymatic activity in the activated-sludge floc matrix, Appl. Microbiol. Biotechnol. 43 (4) (1995) 755-761. 
[24] P. Pagácová, et al., Denitrification in USB reactor with granulated biomass, Bioresour. Technol. 101 (1) (2010) 150-156.

[25] Y. Xue, et al., Effects of a higher hydraulic shear force on denitrification granulation in upflow anoxic sludge blanket reactors, Biochem. Eng. J. 105 (2016) 136-143

[26] Y.Q. Liu, Y. Liu, J.H. Tay, The effects of extracellular polymeric substances on the formation and stability of biogranules, Appl. Microbiol. Biotechnol. 65 (2) (2004) 143-148.

[27] R. Zhu, et al., Performance and surface characteristics of sludge operated at increasing organic loads after aerobic granulation, the 2nd International Conference on Bioinformatics and Biomedical Engineering (2008).
C.H. Tan, et al., The role of quorum sensing signalling in EPS production and the assembly of a sludge community into aerobic granules, ISME J. 8 (6) (2014) 1186-1197.

[29] A.J. Li, B.L. Hou, M.X. Li, Cell adhesion, ammonia removal and granulation of autotrophic nitrifying sludge facilitated by $\mathrm{N}$-acyl-homoserine lactones, Bioresour. Technol. 196 (2015) 550.

[30] H. Lu, K. Chandran, D. Stensel, Microbial ecology of denitrification in biological wastewater treatment, Water Res. 64 (7) (2014) 237-254

[31] Y. Liu, J.H. Tay, State of the art of biogranulation technology for wastewater treatment, Biotechnol. Adv. 22 (7) (2004) 533

[28] 